\title{
A Text Mining Analysis of Central Bank Monetary Policy Communication in Nigeria
}

\begin{abstract}
Mohammed M. Tumala ${ }^{1}$ and Babatunde S. Omotosho ${ }^{2, \dagger}$
This paper employs text-mining techniques to analyse the communication strategy of the Central Bank of Nigeria (CBN) during the period 20042019. Since the policy communique released after each meeting of the $C B N$ 's monetary policy committee (MPC) represents an important tool of central bank communication, we construct a corpus based on 87 policy communiques with a total of 123, 353 words. Having processed the textual data into a form suitable for analysis, we examined the readability, sentiments, and topics of the policy documents. While the CBN's communication has increased substantially over the years, implying increased monetary policy transparency; the computed Coleman and Liau readability index shows that the word and sentence structures of the policy communiques have become more complex, thus reducing its readability. In terms of monetary policy sentiments, we find an average net score of 10.5 per cent, reflecting the level of policy uncertainties faced by the MPC over the sample period. In addition, our results indicate that the topics driving the linguistic contents of the communiques were influenced by the Bank's policy objectives as well as the nature of shocks hitting the economy per period.
\end{abstract}

Keywords: Central bank communication, Text mining, Monetary policy JEL classification: E52, E58, E32, E61

DOI: $10.33429 /$ Cjas.10219.3/6

\subsection{Introduction}

Central bank communication has evolved over the years as an important component of monetary policy design and execution. According to Blinder et al., (2008), central bank communication refers to the quantity and quality of information made available to the public regarding the central bank's monetary policy objectives and strategy; and its perception

\footnotetext{
${ }^{1}$ Corresponding Author: Statistics Department, Central Bank of Nigeria, Abuja. mmtumala@cbn.gov.ng.

${ }^{2}$ The authors are staff of Statistics Department, Central Bank of Nigeria, Abuja. bsomotosho@cbn.gov.ng.

${ }^{\dagger}$ The views expressed in this paper are purely those of the authors, and do not represent the views of the Central Bank of Nigeria.
} 
on economic outlook as well as signals about future policy trajectory. Thus, the development of appropriate communication strategies has become popular among central banks, especially as a means of shaping market expectations. As argued by Coenen (2017), the increased popularity of central bank communication derives from the need for greater monetary policy transparency as a strategic requirement for an inflation targeting monetary policy framework. More so, the growing level of operational independence conceded to central banks globally encourages the need for increased transparency. Consequently, an increasing number of central banks have developed strategies for regularly communicating not only their policy decisions to the public but also the reasoning behind such decisions ${ }^{3}$. Several channels are usually adopted for such communication, including but not limited to monetary policy reports, minutes of monetary policy meetings, post-meeting briefings by central bank governors and speeches by Monetary Policy Committee (MPC) members.

Recognising the crucial roles of central bank communication in monetary policy effectiveness, many central banks have developed communication strategies to systematically disseminate their policy objectives and decisions to the public. For instance, the Bank of Canada (BoC) adopted a system of fixed announcement dates for its interest rate decisions in November 2000 under which the monetary policy meeting takes place eight times a year. At four of such meetings, a monetary policy report is published where the BoC explains its monetary policy decisions, including risks to its inflation outlook. Similarly, the Governing Council of the European Central Bank holds its monetary policy meeting every six weeks, with the ECB President conducting a press conference after each meeting to explain its monetary policy decisions from a prepared statement.

In the case of the US, the Federal Reserve Bank (US Fed), eight regular FOMC meetings are held each year based on a pre-scheduled calendar. The FOMC's communication strategy involves issuing a policy statement after each meeting while the minutes of the meetings are released to the public three weeks after the policy decision date. Similar monetary policy communication strategies are in place in several other central banks around the world, including the Bank of England, Bank of Japan, Bank of

\footnotetext{
${ }^{3}$ Further discussions on the roles of central bank communication can be found in Huang (2007), Hoeberichts et al. (2008).
} 
Korea, the Sveriges Riskbank, the Bank of Thailand, the Central Bank of the Republic of Turkey, the Reserve Bank of Australia, the Bank of Canada, the Reserve Bank of New Zealand, South African Reserve Bank, amongst others. The Central Bank of Nigeria's (CBN) monetary policy committee (MPC) meets regularly based on a pre-announced calendar of meetings released annually. The outcomes of the regular meetings are communicated to the public through a Policy Communique read in a press conference by the Governor. The Communique is then published immediately on the Bank's website (Sanusi, 2011) ${ }^{4}$. So far, 127 MPC meetings have been held while the policy Communiques for meeting numbers 30 to 127 held during 2004 -2019 have been published.

In line with the increased level of communication among central banks, a new but growing body of literature has focused on the extraction of useful insights from monetary policy documents using different text mining techniques (see Shirota, 2015; Bruno, 2016; Kahveci and Odabas, 2016; Luangaram and Wongwachara, 2017; Oshima and Matsubayashi, 2018; Park et al., 2019; Shapiro and Wilson, 2019; Omotosho, 2020). According to Blinder et al. (2008), different methods are available for the analysis of central bank communication; including the indirect approach (whereby financial market reactions to policy announcements are measured using event windows), and a direct approach (whereby the researcher provides a subjective assessment of central bank communication by manually reading through the policy document and coding its contents into numerical scales). In recent times, the advancement in text mining algorithms provides for a more objective procedure in which the content of many documents are analysed using a computer-based approach. The benefits of applying automated text mining techniques to monetary policy documents are outlined in Bholat, et al. (2015). Despite its usefulness for the design of an effective communication strategy, studies on central bank communication in Nigeria are relatively scanty; with the existing ones employing either the indirect or the direct approach (see Sanusi, 2011; Yahaya and Sanusi, 2012; Umar and Sanusi, 2013; Ekor, 2013).

Against this backdrop, we apply text mining techniques to study Central Bank of Nigeria's monetary policy communication strategy during the period 2004-2019. This study is thus novel in its contribution to literature as it applies the automated text mining approach to textual data from CBN source. To our knowledge, no other study has analysed CBN's monetary

\footnotetext{
${ }^{4}$ The regular monetary policy committee meeting of the CBN holds six times a year
} 
policy communication using this technique. This fully automated method has the advantage of objectivity as it eliminates the subjectivity often associated with the human reading approach (Blei et al., 2003; Hubert and Fabien, 2017). Specifically, we assess the readability of the published policy communiques over time by computing their respective readability scores. Also, we compute the monetary policy sentiment scores to gauge the tone of CBN communication over the sample period. Lastly, a Latent Dirichlet Allocation model is estimated via the collapsed Gibbs sampling algorithm to identify the key topics driving monetary policy communication during the sample period.

The paper is organized into five sections. In the next section, we review relevant literature on the application of text mining techniques to central bank communication. In the third section, the text mining procedures adopted as well as the data used for the empirical investigation are discussed. The results are presented in section four while section five concludes the paper.

\subsection{Review of Literature}

An effective communication strategy is crucial for any central bank to successfully address the typical problems confronting it (Woodford, 2005; Poole, 2005). Prior to the 1990s, Woodford argued that the US Fed adopted a monetary policy making approach which was shrouded in secrecy in order to regularly take the markets by surprise. The era of Alan Greenspan was, however, characterised by the willingness of the Federal Open Market Committee (FOMC) to communicate openly about its current and future policy actions. There appears now to be a consensus in literature that effective central bank communication is important for shaping market expectations, determining asset prices, achieving macroeconomic stability, improving the predictability of future monetary policy decisions, and enhancing policy dialogue with the public (Blinder, 1999; Bernanke and Reinhart, 2004; Sturm and De Haan, 2011; Berger et al., 2011; and Oshima and Matsubayashi, 2018).

Central bank communication has been studied from both theoretical and empirical perspectives (Bernanke et al., 1997; Blinder, 1999; Clarida et al., 2000; Woodford, 2002; Geraats, 2002; Bernanke and Reinhart, 2004; Ehrmann and Fratzscher, 2005; Blinder et al., 2008; Hoeberichts et al., 2008; Eusepi, 2010; Eusepi and Preston, 2010; Berger et al., 2011; Sturm and De Haan, 2011; Demiralp et al., 2012; Apel and Grimaldi, 2014; 
Bergholt, 2014; Luangaram and Sethapramote, 2016; Bruno, 2016; Coenen et al., 2017). For instance, Eusepi and Preston (2010) studied the role of central bank communication in the stabilisation of agents' expectations using a fully specified new Keynesian model. It was found that the Taylor rule is in itself not sufficient to achieve macroeconomic stability without effective monetary policy communication. In other words, the Taylor principle is successful at anchoring market expectations only when the central bank's communication strategy involves presenting the precise details of monetary policy ${ }^{5}$. On the other hand, Huang (2007) argued that in an uncertain world, complete public disclosure by monetary authorities may undermine the effects of bounded rationality. Thus, within his contextualisation, he agreed with Poole's (2005) view that monetary policy transparency should be characterised by "accurately conveying accurate information including the information market participants need to form opinions on monetary policy that are as complete as possible".

According to Blinder et al. (2008), central bank communication plays two roles in the management of expectations: "creating news" - under which central bank pronouncements influence asset prices by shaping agents' expectations; and "reducing noise" - under which central bank communication helps to predict monetary policy actions, thereby reducing financial market volatility. Thus, many studies have noted that the effectiveness of monetary policy communication could be gauged by its ability to correctly shape market expectations (Blinder, 1999; Woodford, 2002; Blinder et al., 2008; Hoeberichts et al., 2008). Naghdaliyev (2011) argued that the need to effectively manage expectations constitutes one of the key policy challenges of the post 2008 global financial crisis. He further emphasised that the provision of appropriate information to the public about central bank policy actions helps reduce rather than exacerbate economic uncertainties, thus making central bank communication the primary tool for expectations management.

\footnotetext{
${ }^{5}$ Huang (2007) and Coenen et al. (2017) provide further discussions on the roles of central bank communication in expectations management
} 


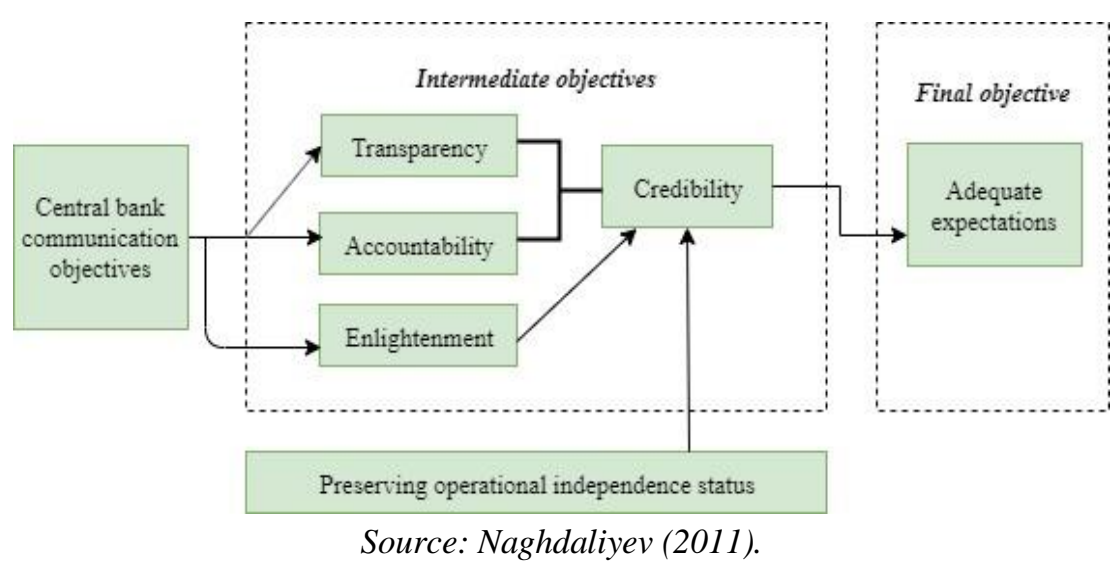

Figure 1: Central bank communication objective

In Naghdaliyev's (2011) argument, it is important for central banks to have clear communication objectives in order to avoid information overload that could lead to the "deterioration of the rational decisionmaking process by the public". While the final objective relates to the effective management of expectations, the intermediate objectives of central bank communication should necessarily encompass transparency ${ }^{6}$, accountability, and credibility (Figure 1). Of the three intermediate objectives, Naghdaliyev (2011) states that credibility is the most crucial, noting that the ability of the central bank to adequately shape expectations rests on its credibility. Thus, the crucial link between central bank communication and central bank credibility represents one of the reasons why communication has become an important aspect of monetary policy. Consequently, a growing body of literature has focused on the assessment of communication strategies amongst central banks. In this section, we present a non-exhaustive review of such studies with particular attention to those that employed text mining techniques.

In line with Naghdaliyev's (2011) concern about expectations management in the aftermath of the global financial crisis (GFC), a few studies have compared the communication strategies of some central banks before and after the GFC. For instance, Kahveci and Odabas (2016) analysed monetary policy statements from the Fed, ECB and Central Bank of Turkey (CBRT) in order to investigate the linguistic content of their communication before and after the 2008 GFC. Their results showed that the Fed's policy statements have recorded less optimistic tone and more certainty tone in the aftermath of the crisis while the tones of the policy

\footnotetext{
${ }^{6}$ According to Geraats (2002), the five facets of monetary policy transparency include political, economic, procedural, policy and operational transparency.
} 
statements published by the ECB and CBRT have remained unchanged. Also, in a study of five central banks (the Reserve Bank of Australia, the Bank of Canada, the Reserve Bank of New Zealand, the Bank of England and the U.S. Federal Reserve), Siklos (2013) investigated whether the linguistic content of central bank communication has changed since the GFC. The monetary policy documents published by these central banks were analysed using text mining tools and it was found that concerns relating to financial stability and economic uncertainties were quite high during the crisis.

Quite many studies have examined the relationship between central bank communication and macroeconomic out-turns. For instance, Shapiro and Wilson (2019) applied text mining techniques to analyse the transcripts of the FOMC meetings, the minutes of their meetings as well as speeches of FOMC members for the period 1986-2013. They extracted a measure of monetary policy sentiment from the group of documents considered and showed that FOMC's negative sentiments were inversely related to United States' output growth. In a bid to assess the implications of BOJ's communication on the performance of the Japanese economy, Luangaram and Sethapramote (2016) also extracted useful text-based indicators from the Bank's monetary policy documents using text mining techniques. They found that the inclusion of central bank communication indicators into their structural vector autoregression model increased the response of output to an interest rate shock. In a similar study for the Japanese economy, Oshima and Matsubayashi (2018) investigated the effects of BOJ's communication on the Japanese financial market. The authors obtained textual data collected from the published minutes of the BOJ's Monetary Policy Meeting during April 2013 to September 2017 and estimated a Latent Dirichlet Allocation (LDA) model in order to unravel the hidden topics in the documents. It was found that the estimated topics significantly impacted market reactions, especially on the days the minutes were published. To study the relationship between monetary policy sentiment and the term structure of private short-term interest rate expectations, Hubert and Fabien (2017) applied the computational linguistics approach to derive monetary policy sentiment scores from policy documents published by the ECB and the Fed. Their results showed that positive shocks to monetary policy sentiment increase private interest rate expectations both in the US and the euro area. 
In order to evaluate the communication strategy of central banks, some studies have employed text mining to investigate the readability of monetary policy documents. In a study of the BoC's communication strategy, Binette and Tchebotarev (2019) computed the readability of BoC's monetary policy report. Their results showed that the published monetary policy reports were slightly more complicated for an average Canadian to understand. They also showed that important macroeconomic events in Canada were associated with increased levels of lexical innovation in the policy reports. Similarly, Coenen et al. (2017) studied the readability of ECB's monetary policy statements and showed, using the Flesch- Kincaid reading grade level statistic, that the ECB's monetary policy statements have become easier to understand over time. In a crosscountry study, Luangaram and Wongwachara (2017) analysed monetary policy statements across 22 central banks, including the Fed, in order to derive insights regarding their readability, topics and tones. It was found that there have been increased readability of the monetary policy reports published by the central banks considered. However, they also observed that the documents have become more complex due to the increased use of technical terms. In order to compare the communication strategies of the Fed and ECB as documented in their monetary policy reports, Farina et al. (2018) employed computational linguistics tools and found that the strategies of the two central banks were quite similar.

With regards to the predictability of monetary policy actions using central bank communication, Hayo and Neuenkirch (2011) applied text mining techniques and showed that prior to the introduction of fixed announcement dates, the $\mathrm{BoC}$ communications were more useful in predicting future policy moves. Their results further revealed that the communications by the U.S. Fed outperformed BoC's communication indicators in explaining interest rate decisions in Canada. In a related study for Sweden, Apel and Grimaldi (2012) analysed the published minutes of the monetary policy meetings to predict future Riskbank's decisions. Having derived a text-based net index of hawkishness from each of the minutes, they showed that interest rate hikes in Sweden were associated with high degree of net hawkishness in Riskbank's communication. It was further shown that the minutes of the monetary policy meetings were more useful than the monetary policy report in the prediction of the future path of Riskbank's policies. Also, Sturm and De Haan (2011) investigated the usefulness of ECB's communication in enhancing monetary policy prediction within the framework of an 
augmented Taylor rule model. They applied text mining techniques on the statements issued by the ECB President at the end of each ECB policy meeting and showed that the text-based indicators derived from the ECB communication provided additional information for predicting the Banks future policy decisions. In the case of the Bank of Japan (BOJ), Luangaram and Sethapramote (2016) augmented the standard Taylor-type rule specifications with text-based indicators generated from the BOJ's monetary policy reports. Their results also showed that the computed indicators improved the performance of the Taylor-type rule specifications in predicting future policy interest rate in Japan. Similar findings were obtained by Park et al. (2019) for the Bank of Korea (BOK) and Demiralp et al. (2012) for the Central Bank of Turkey (CBRT).

Text mining techniques have also been applied to other areas related to monetary policy; including central bank communication during banking reforms (Amadxarif et al., 2019), financial instability prediction using computed text-based financial sentiment (Nyman and Tuckett, 2015), sentiment score of financial stability reports (Correa et al., 2017), the role of financial stability on stock market returns (Born et al. 2014), etc. A couple of studies have also applied text mining techniques to data extracted from the social media with a view to generating meaning insights for economic predictions. These include studies on the role of twitter sentiment in the determination of stock price returns (Mittal and Goel, 2012; Sumbureru, 2013; Khatri et al., 2014; Ranco et al., 2015; and Kumar et al., 2015), social media sentiment and consumer confidence (Daas and Puts, 2014); sentiment indicators and exchange rate prediction (Hopper, 1997; Crone and Koeppel, 2014; Janetzko, 2014; Ozturk and Ciftci, 2014; Plakandaras et. al., 2015; Iwantoro and Koesrindartoto, 2017), amongst others. With regards to tourism development, Barbagallo et. al., (2012) analysed twitter content using text mining and found that negative posts are more influential than positive ones. In terms of text mining applications to governance issues, Amusa et al. (2016) used twitter data to analyse the sentiments of Nigerians about the country's federal government.

Studies on the analysis of central bank communication in Nigeria are still relatively scanty. The few existing ones include Ekor et al. (2013), which investigated the implications of central bank communication for monetary policy effectiveness. Using data for the period 1985Q1-2013Q2, they characterised central bank communication by manually reading through 
CBN's monetary policy documents and showed that improved central bank communication leads to lower price volatility. Adopting a similar methodology, Sanusi (2011) developed an indicator of monetary policy stance by manually reading through the published minutes and communiques of the CBN's MPC. It was found that the Nigeria Interbank Offer Rates (NIBOR) for different maturities recorded higher volatilities during MPC meeting weeks. Also, in another study aimed at investigating the relationship between central bank communication and the stock market, Umar and Sanusi (2013) showed that improved communication by the CBN reduced stock market volatility during the period 2007-2011. These studies applied the human reading approach to the analysis of central bank communication, an approach that is limited by its subjectivity and cumbersomeness. More so, the human reading approach does not lend itself to the extraction of deep insights from the monetary policy documents. We avoid these shortcomings in our paper by adopting an automated text mining approach.

\subsection{Data and Methodology}

This section describes the textual data used for our analysis. In addition, it enumerates the data processing steps as well as the automated text mining procedure employed. The benefit of our chosen methodology lies in the use of computer-enabled algorithms to process large textual data in a more effective and efficient manner than can be achieved by human reading (Bholat et al. 2015).

\subsection{Data}

The textual data used for our analysis was sourced from the policy communiques published on the CBN's website at https://www.cbn.gov.ng/documents/mpc.asp. 
Table 1: CBN policy communique word count, 2004-2019

\begin{tabular}{|c|c|c|c|c|c|c|c|c|}
\hline $\begin{array}{c}\text { Communique } \\
\text { No. }\end{array}$ & $\begin{array}{l}\text { Meeting } \\
\text { month }\end{array}$ & $\begin{array}{l}\text { Word } \\
\text { count }\end{array}$ & $\begin{array}{c}\text { Communique } \\
\text { No. }\end{array}$ & $\begin{array}{l}\text { Meeting } \\
\text { month }\end{array}$ & $\begin{array}{l}\text { Word } \\
\text { count }\end{array}$ & $\begin{array}{c}\text { Communique } \\
\text { No. }\end{array}$ & $\begin{array}{l}\text { Meeting } \\
\text { month }\end{array}$ & $\begin{array}{l}\text { Word } \\
\text { count }\end{array}$ \\
\hline 32 & Jan-04 & 560 & 68 & Mar-10 & 1,970 & 101 & May-15 & 1,824 \\
\hline 33 & Mar-04 & 499 & 70 & May-10 & 2,172 & 102 & Jul-15 & 1,434 \\
\hline 34 & Apr-04 & 557 & 72 & Sep-10 & 2,169 & 103 & Sep-15 & 1,771 \\
\hline 35 & May-04 & 446 & 73 & Nov-10 & 1,529 & 104 & Nov-15 & 1,694 \\
\hline 36 & Jun-04 & 281 & 74 & Jan-11 & 1,877 & 105 & Jan-16 & 1,833 \\
\hline 37 & Jul-04 & 283 & 75 & Mar-11 & 1,383 & 106 & Mar-16 & 1,995 \\
\hline 38 & Sep-04 & 254 & 76 & May-11 & 1,240 & 107 & May-16 & 2,319 \\
\hline 39 & Oct-04 & 223 & 77 & Jul-11 & 1,434 & 108 & Jul-16 & 2,123 \\
\hline 40 & Nov-04 & 291 & 78 & Sep-11 & 1,558 & 109 & Sep-16 & 2,473 \\
\hline 41 & Dec-04 & 369 & 79 & Oct-11 & 1,174 & 110 & Nov-16 & 1,875 \\
\hline 42 & Jan-05 & 365 & 80 & Nov-11 & 2,092 & 111 & Jan-17 & 1,667 \\
\hline 46 & Jun-06 & 793 & 81 & Jan-12 & 2,114 & 112 & Mar-17 & 1,654 \\
\hline 47 & Aug-06 & 679 & 82 & Mar-12 & 1,741 & 113 & May-17 & 1,399 \\
\hline 50 & Jun-07 & 842 & 83 & May-12 & 2,097 & 114 & Jul-17 & 1,860 \\
\hline 51 & Aug-07 & 709 & 85 & Sep-12 & 2,073 & 115 & Sep-17 & 2,035 \\
\hline 52 & Oct-07 & 686 & 86 & Nov-12 & 2,475 & 116 & Nov-17 & 1,661 \\
\hline 53 & Dec-07 & 736 & 87 & Jan-13 & 2,325 & 117 & Apr-18 & 1,729 \\
\hline 54 & Feb-08 & 675 & 88 & Mar-13 & 1,840 & 118 & May-18 & 2,244 \\
\hline 55 & Apr-08 & 684 & 89 & May-13 & 1,773 & 119 & Jul-18 & 2,349 \\
\hline 56 & Jun-08 & 817 & 90 & Jul-13 & 1,418 & 120 & Sep-18 & 1,832 \\
\hline 57 & Aug-08 & 952 & 91 & Sep-13 & 1,550 & 121 & Nov-18 & 1,916 \\
\hline 58 & Sep-08 & 420 & 92 & Nov-13 & 1,694 & 122 & Jan-19 & 1,953 \\
\hline 59 & Dec-08 & 842 & 93 & Jan-14 & 1,638 & 123 & Mar-19 & 1,865 \\
\hline 60 & Jan-09 & 317 & 94 & Mar-14 & 1,500 & 124 & May-19 & 1,872 \\
\hline 61 & Feb-09 & 924 & 95 & May-14 & 1,411 & 125 & Jul-19 & 1,499 \\
\hline 62 & Apr-09 & 799 & 96 & Jul-14 & 1,634 & 126 & Sep-19 & 1,566 \\
\hline 63 & May-09 & 366 & 97 & Sep-14 & 1,501 & 127 & Nov-19 & 2,059 \\
\hline 65 & Sep-09 & 943 & 98 & Nov-14 & 2,941 & & Total & 123,353 \\
\hline 66 & Nov-09 & 1,467 & 99 & Jan-15 & 1,441 & & & \\
\hline 67 & Jan-10 & 1,822 & 100 & Mar-15 & 1,487 & & & \\
\hline
\end{tabular}

\section{Source: Authors' compilation}

Each release of the policy communique presents the MPC's analyses of global and domestic economic developments, the outlook for the global and domestic economies, the Committee's considerations, and the Committee's decisions. The CBN's Policy Communique thus disseminates useful information not only about the Bank's monetary policy decisions, but also the arguments behind those decisions. Therefore, for this study, our corpus consists of 87 MPC communiques with a total word count of 123, 353 words (Table 1).

A couple of pre-processing operations are performed to convert our corpus into a structured form that is suitable for text mining analysis. In the first step, we instruct our program to remove numbers, punctuations, white spaces, and special characters (such as " "” and "-") from the documents. Secondly, all the characters in the corpus are converted to lower case to ensure that same words are not counted as different terms across the documents. In the third stage, we remove English stop words such as "for", "in", "the", "about", "this", "therefore" as they add no value to our analysis. Furthermore, certain redundant words such as "billion", "trillion", "period", "annualised", etc are excluded from the data set. In the fourth step, we stem the corpus by dropping letters or 
combination of letters such as "e", "c", "ing", "ed" from the end of words to generate uniqueness.

As suggested by Gefen et al. (2017), these steps are applied to all the documents in the same order and based on the same rules. The data preprocessing procedure is crucial for our text analysis as it enables us to generate a clean textual data set that allows for the identification of the key topics driving the evolution of documents in the corpus. After completing the pre-processing procedure, 51, 408 words were dropped leaving a total number of 71, 945 words for analysis. In the last step, our corpus of text documents is converted into a term by document matrix, such that each cell, $c_{i, j}$, in the matrix represents a weighted frequency of the word $i$ in the document $j$.

\subsection{Readability Analysis}

To evaluate how understandable, the CBN policy communiques are, we compute the readability index for each document in the corpus following Coleman and Liau (1975). Based on an analysis of the word and sentence structures of the documents in a corpus, the Coleman-Liau Readability Index (CLI) indicates the percentage of deletions in a document that can be filled in by a college undergraduate. Therefore, a higher value of CLI for a document implies that it is relatively easy to read such a document while a low CLI shows that the document is complex. The index is computed as:

$C L I=141.8401-0.214590 \times \frac{100 \times N_{c h}}{N_{w}}+1.079812 \times \frac{N_{s t} \times 100}{N_{w}}$

where $N_{c h}$ denotes the number of characters, $N_{s t}$ represents the number of sentences while $N_{w}$ denotes the number of words in the document. It is clear from equation (1) that the CLI is determined based on word difficulty in the document (i.e. the number of characters per word) and the sentence difficulty (i.e. the number of words per sentence).

\subsection{Sentiment Analysis}

According to Miner et al. (2012), the opinions, and affective states of people reflected in a corpus of textual data can be determined based on sentiment analysis. Basically, the procedure for sentiment analysis involves categorising the opinion expressed in a document as positive, neutral, or negative. We apply this technique to our data set in order to study the evolution of monetary policy sentiments as expressed in the policy communiques. The monetary policy sentiment score summarises 
the perception of the MPC regarding the upside and downside risks to the achievement of the Bank's policy objectives. Following the approach in Binette and Tchebotarev (2019), the CBN's monetary policy net sentiment score (MPSS) for each document in our corpus is derived as:

$$
\text { MPSS }=\frac{N_{\text {postive }}-N_{\text {negative }}}{N_{\text {total }}} \times 100
$$

where $N_{\text {postive }}$ denotes the number of words expressing positive sentiments, $N_{\text {negative }}$ is the number of words expressing negative sentiments, and $N_{\text {total }}$ is the total number of words in the document. Any positive sentiment term used in a document takes the value of +1 while a negative sentiment term takes a value of -1 . It is implied in equation (2) that a value of MPSS > 0 indicates positive sentiments while MPSS < 0 signifies the expression of negative sentiments. The computed MPSS enables us to derive useful insights regarding the CBN's perception on the direction of change in economic conditions.

\subsection{Topic Extraction}

The Latent Dirichlet Allocation (LDA) modelling approach developed by Blei et al. (2003) is used to classify the texts contained in our corpus into meaningful categories that characterise the topics in the CBN Communiques. The model is implemented based on an assumption that each document is determined by a set of topics while each topic is in turn determined by a set of words (Blei et. al., 2003). Thus, the LDA is a probabilistic model that assumes that each document is generated through a latent probabilistic generative process. This sort of probabilistic generative process is then used to determine the probabilities of a word and a document belonging to a topic ${ }^{7}$. Following the procedure outlined in Calvo-González et al., (2018) and Shirota et al. (2015), the LDA generative process for our corpus is described in the following steps:

Step 1: For each topic $k$, we draw a distribution $\varphi_{k}$ over words according to a Dirichlet distribution $\sim \operatorname{Dir}(\beta)$, where $\beta$ is the parameter of the Dirichlet prior on the per-topic word distribution. A high value of $\beta$ is interpreted to mean that each topic comprises most of the words in the corpus, whereas a low $\beta$ means that each topic features fewer words.

\footnotetext{
${ }^{7}$ For a detailed tutorial on topic modelling using LDA, see Debortoli et al. (2016)
} 
Step 2: For each document $D$ : we draw a vector of topic proportions $\theta_{d}$ according to a Dirichlet distribution $\sim \operatorname{Dir}(\alpha)$, where $\alpha$ is the parameter of the Dirichlet prior on the per-document topic distribution. A high value of $\alpha$ means that each document comprises a mixture of most of the identified topics whereas a low $\alpha$ means that each document features fewer topics.

Step 3: For each of the $N$ words $w_{n}$ : we choose a topic assignment $z_{n}$ based on a multinomial distribution $\sim \operatorname{Multinomial}(\theta)$ according to the topic proportion $\theta_{d}$. Next, we choose a word $w_{n}$ from $p\left(w_{n} \mid z_{n}, \varphi\right)$ based on a multinomial probability conditioned on the topic $z_{n}$; where $z$ represents the per-word topic assignments.

By going through steps $1-3$ above, the distribution of the parameters $\varphi$, $\theta$, and $z$, that are most likely to have governed the generation of the documents in our corpus can then be inferred. Thus, given our documents and the Dirichlet priors ( $\alpha$ and $\beta$ ), the LDA model computes the posterior distribution of the latent variables as follows:

$$
P(\theta, z, \varphi \mid w, \alpha, \beta)=\frac{P(\theta, z, \varphi \mid \alpha, \beta)}{P(w \mid \alpha, \beta)}
$$

It is computationally costly to calculate the maximum likelihood for equation (3) since the size of the estimation space is the number of topics, $k$, to the power of the dimension of the vocabulary, $v$, in the corpus. In line with the practice in existing literature, we circumvent this problem using the collapsed Gibbs sampling algorithm to approximate the posterior distributions of the hidden variables given in equation (3) by running 5,000 iterations ${ }^{8}$. Once the posterior estimates for $\varphi$ and $\theta$ are derived, the algorithm then returns the topic representation of each document in the corpus. The number of topics in our corpus is heuristically taken as six $(k=6)$.

\subsection{Results}

4.1 Frequency distribution of words in the term document matrix Table 2 presents the cumulative frequency distribution of words in our term document matrix (TDM) analysed by their character lengths. As can

\footnotetext{
${ }^{8}$ As noted by Shirota et al. (2015), the collapsed Gibbs sampling algorithm is a useful procedure for approximating posterior distributions that are difficult to compute directly.
} 
be seen, there are 1, 699 unique words in the TDM with a minimum character length of 3 and a maximum character length of 14 .

Table 2: Cumulative frequency of words by their character length

\begin{tabular}{ccrcc}
\hline Word length & Freq & \multicolumn{1}{c}{ Cum.freq } & Percent & Cum.percent \\
\hline 3 & 96 & 96 & 5.65 & 5.7 \\
4 & 280 & 376 & 16.48 & 22.1 \\
5 & 329 & 705 & 19.36 & 41.5 \\
6 & 396 & 1,101 & 23.31 & 64.8 \\
7 & 278 & 1,379 & 16.36 & 81.2 \\
8 & 177 & 1,556 & 10.42 & 91.6 \\
9 & 76 & 1,632 & 4.47 & 96.1 \\
10 & 37 & 1,669 & 2.18 & 98.2 \\
11 & 12 & 1,681 & 0.71 & 98.9 \\
12 & 11 & 1,692 & 0.65 & 99.6 \\
13 & 6 & 1,698 & 0.35 & 99.9 \\
14 & 1 & 1,699 & 0.06 & 100.0 \\
\hline
\end{tabular}

Source: Authors' computation

The published policy communiques of the CBN are dominated by sixcharacter words with a frequency of 396 or 23.3 per cent. This is followed by five-character words with a frequency rate of 19.4 per cent. Overall, about 65.0 per cent of the words contained in our TDM are between $3-6$ characters in length. It is expected that the topics in our documents will be largely influenced by words within this frequency category. However, words with character lengths above 10 accounts for only 1.8 per cent, implying that the CBN communication is expressed in rather not too complex words.

\subsection{Has the CBN communicated more over the years?}

Having subjected our corpus to the pre-processing procedures outlined in sub-section 3.1, about 51, 408 words were excluded from our analysis, leaving us with a balance of 71, 945 words. In Table 3, we show the annual averages of the word counts for the published policy communiques. As can be seen, the word count for the published policy communiques have increased systematically over the years, indicating increased monetary policy transparency. 
Table 3: Annual average of communique word count

\begin{tabular}{rr}
\hline Year & $\begin{array}{r}\text { Average word } \\
\text { count of policy } \\
\text { communique }\end{array}$ \\
\hline 2004 & 201 \\
2005 & 186 \\
2006 & 402 \\
2007 & 394 \\
2008 & 418 \\
2009 & 470 \\
2010 & 1,122 \\
2011 & 913 \\
2012 & 1,203 \\
2013 & 1,012 \\
2014 & 1,044 \\
2015 & 965 \\
2016 & 1,230 \\
2017 & 1,006 \\
2018 & 1,197 \\
2019 & 1,084 \\
\hline
\end{tabular}

Source: Authors' computation

The annual average word count for the policy communiques increased from 201 words in the year 2004 to 1, 084 words in 2019. It is important to note that the annual average word count for the policy document increased substantially from 470 words in 2009 to 1,122 in 2010, following the commencement of the term of a new CBN Governor. The highest annual word count average was recorded in 2016 (1, 230 words), a year the economy was in recession. This seems to suggest that the CBN tends to communicate more during periods of economic turbulence. This observed behaviour is in line with the findings of Luangaram and Wongwachara (2017), which showed that central banks communicate more during difficult periods.

Furthermore, Figure 2 shows the distribution of words contained in the processed corpus over the 87 policy communiques analysed. The red horizontal line indicates the average word count for the documents, which stands at about 827 words. Over the sample period, the highest word count ( 1,837 words) was recorded by Communique No. 98 issued after the MPC meeting of November 24-25, 2014. This coincided with the period the MPC raised concerns regarding the increasing vulnerabilities of the 
Nigerian economy as well as the declining external reserves and the mounting pressures in the foreign exchange market. Consequently, the meeting made significant decisions that were communicated in Communique No. 98, including an increase in MPR from 12.0 to 13.0 per cent; increase in private sector deposit cash reserve ratio from 15.0 to 20.0 per cent; and increase in the midpoint of the official window of the foreign exchange market from $155 /$ US\$ to $168 /$ US\$.

The circles drawn on Figure 2 represent four clusters of periods during which the word count for the CBN policy communiques were substantially above the sample average. The cluster of word count spikes for the policy communiques published during the period identified by the first circle corresponds to the need for increased central bank communication in the aftermath of the global financial crisis as well as a possible change in the $\mathrm{CBN}$ communication strategy under the regime of a new CBN Governor. More so, the banking sector reforms of 2009/2010 embarked upon by the Sanusi-led CBN as well as the need for appropriate monetary policy response to elections-related economic uncertainties required greater central bank communication during the period. Consequently, the MPR was increased seven times within the cluster of periods represented under the first circle. The second circle corresponds to the period of increased concerns by the MPC regarding inflationary shocks resulting from non-monetary sources such as the incidence of floods, the upward adjustment in electricity tariffs during 2012 as well as the increase in the price of PMS.

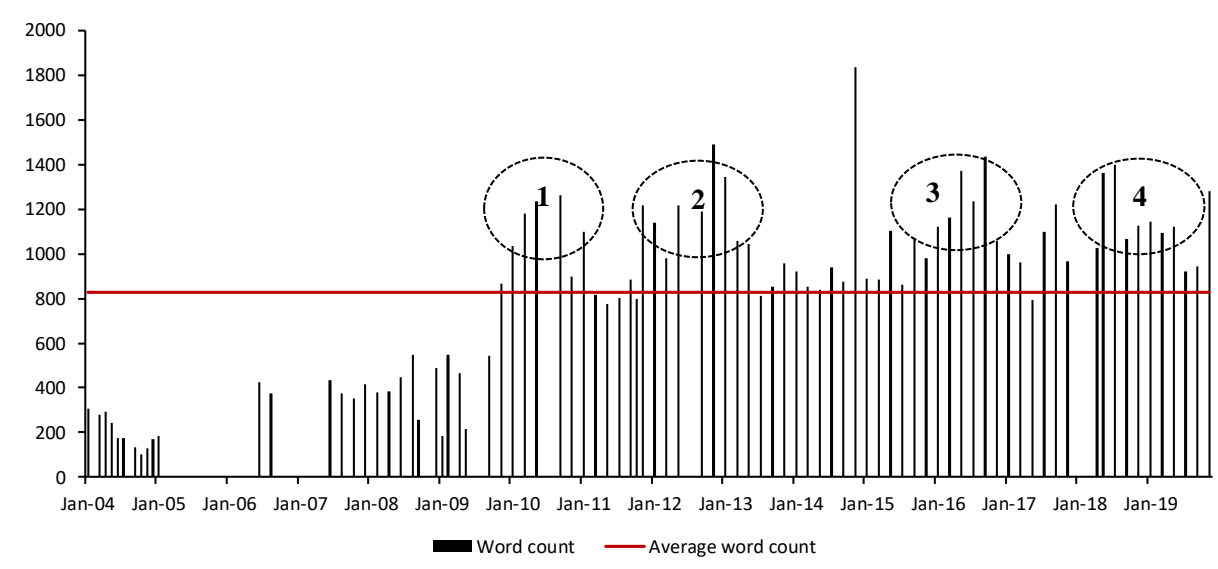

Source: Authors' computation

Figure 2: Word count of CBN's monetary policy communiques, $2004-$ 2019 
As earlier noted, the third circle corresponds to the 2016 economic recession. This seems to suggest that the $\mathrm{CBN}$ was conscious of the need to communicate more whenever significant monetary policy changes were required to stabilise the economy. For instance, the MPR was increased twice during the period January - July, 2016. Thus, the MPC's increased communication during such a difficult time tend to suggest the CBN's recognition of the need to express its perception about macroeconomic developments, reiterate its policy objectives, and explain the rationale behind its policy decisions. The fourth circle represents the period of increased advocacy for monetary-fiscal policy coordination in order to further strengthen the country's economic recovery. In the communiques issued during the period, the MPC also expressed concerns about the weak level of intermediation by the deposit money banks as well as the increase in the level of non-performing loans.

In summary, our results show that while central bank communication has increased over time, spikes in the word count for published communiques were associated with notable macroeconomic developments and specific policy concerns confronting the MPC. Also, it appears periods of rapid and consistent increases in the monetary policy rate were associated with increased central bank communication.

\subsection{Readability of CBN Policy Communiques}

To assess the complexity level of central bank communication, we compute the Coleman and Liau (1975) readability index for each of the published policy communique contained in our corpus and the results are plotted in Figure 3. The red dashed line represents the average of the computed index over the sample period, which was 19.1 per cent. This average readability level corresponds to that expected of a college student and other higher qualifications and compares with the level found by Bruno (2017) for the Financial Stability Reports (FSR) published by the Bank of Italy. As can be seen, it appears the level of readability of the policy communiques has declined slightly over the years, starting from an average of 23.2 per cent in 2004 to an average of 17.4 per cent in 2019. This tends to suggest increased complexity in the word and sentence structures of the published policy communiques over time. 


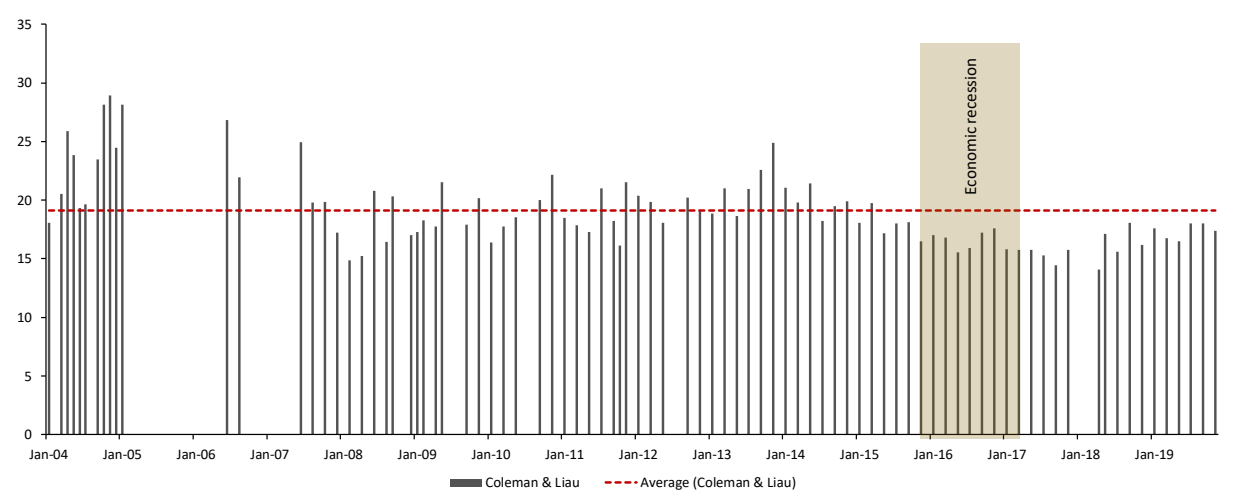

Source: Authors' computation

Figure 3: Coleman and Liau (1975) readability index for CBN policy communiques

Of interest is the steady decline in the readability index since the oil price slump that began in 2014. In this paper, our thesis is that the central bank tends to communicate more during periods of economic and policy uncertainties; and in the process, more complex words and sentences are deployed, which then reduces the readability level of the published policy reports. As can be seen, the readability level of the communiques issued during the 2016 economic recession were below the average for the sample period.

\subsection{What Issues were of Concern to the MPC During the 2004 - 2019 Period?}

To identify the key issues that were of concern to the MPC during the sample period, we analysed the most frequent terms used in the published policy communiques. First, we show a plot of the 25 most used words in our corpus in Figure 4. As can be seen, the most frequent word used in the policy communiques is "growth", occurring about 1, 300 times. Following this are terms such as "market", "policy", "bank", "economic", "exchange", "monetary", "inflation", "prices", "sector", "develop", "increase", etc. It is interesting to note that these most frequent terms are quite related to the policy objectives of the CBN as well as the macroeconomic developments that were significant to the decisions of the monetary policy committee over the sample period. In other words, the MPC focused on economic growth, the foreign exchange market, as well as price developments. These areas of focus for the MPC are consistent with the prescriptions of an appropriate Taylor rule for small open resource-rich economies. 


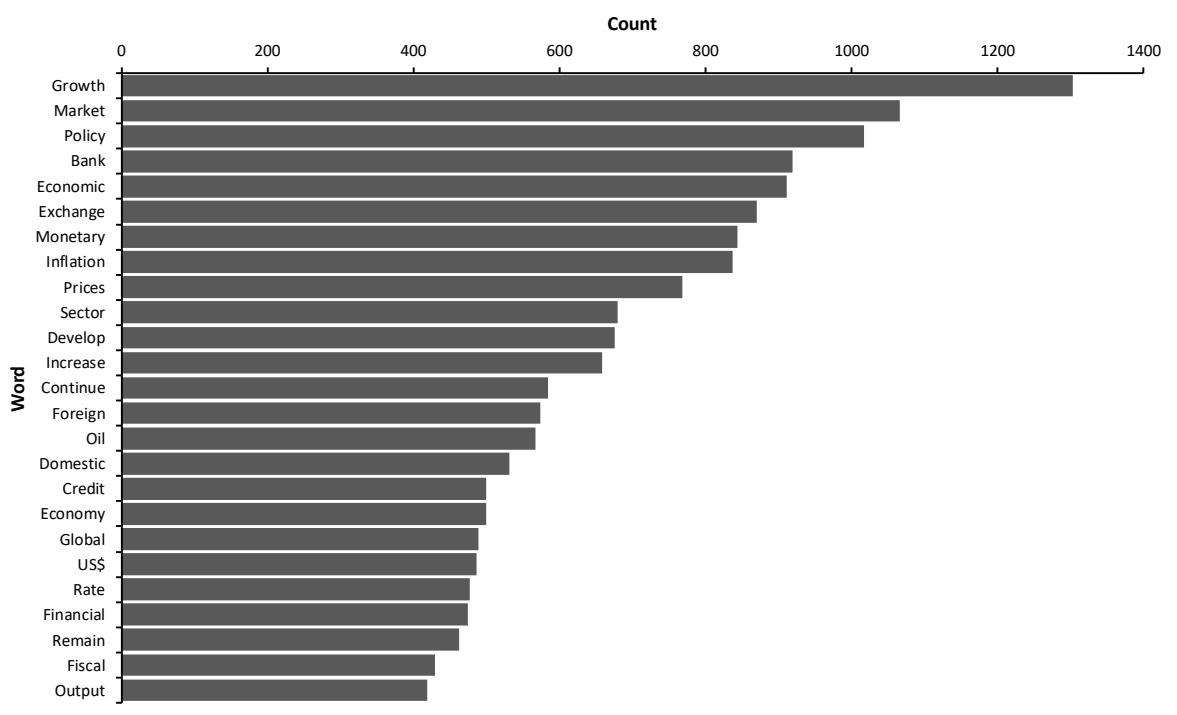

Source: Authors' computation

Figure 4: Frequent terms in the Document Term Matrix (DTM), 2004 2019

Expectedly, oil features as the fifteenth most important term, reflecting the status of the Nigerian economy as an oil exporter. Consequently, volatilities in the crude oil market are expected to generate non-trivial implications for economic growth, exchange rate management as well as the price stability objective of the CBN.

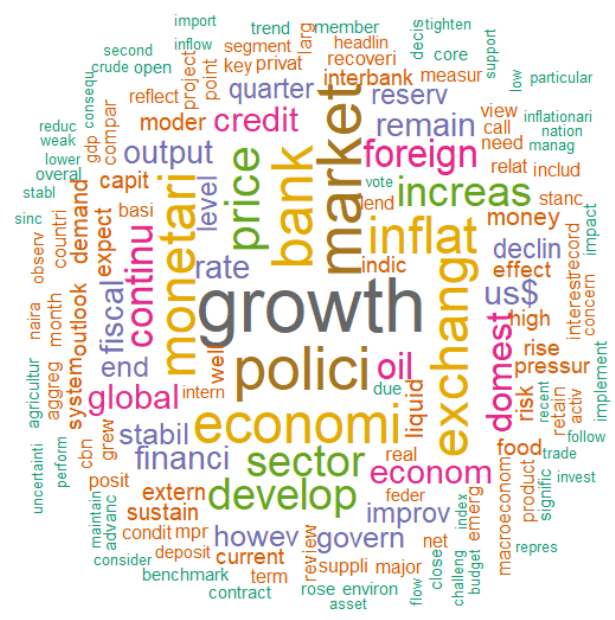

Source: Authors' compilation

Figure 5: Word cloud of the Document Term Matrix (DTM), 2004 2019 
Also, the word cloud shown in Figure 5 presents the most frequent words in our corpus. As described by Bruno (2017), the word cloud is a synthetic picture that highlights the popular terms in a document by resizing their fonts proportionally to their relative frequency (Bruno, 2017). It can be easily observed from Figure 5 that terms such as "growth", "policy", "market", "inflation", "exchange", "oil", "reserves", "fiscal" feature prominently. This buttresses our earlier observation regarding the MPC's concerns about the issues of growth, prices and the exchange rate.

From the analysis conducted in this section, it can be inferred that the need to achieve output, exchange rate, and price stability in the face of global and domestic shocks represented the key concern of the MPC during the 2004-2019 period. Thus, terms such as growth, prices, exchange were copiously mentioned in the published policy communiques. In a more detailed study, for instance, generating the word cloud for each published policy communique could be indicative of how the policy concerns of the monetary policy committee had evolved over the years. However, for space constraint, this is not pursued here. Instead, we proceed to unravel the hidden topics in the group of documents analysed in this paper by discussing the results of the estimated LDA model.

\subsection{Topic Modelling of the CBN Policy Communiques, 2004-2019}

In line with the procedure for estimating LDA models, we heuristically assume that the policy communiques contained in our corpus can be analysed under six topics. These topics are influential in driving the linguistic content of the CBN policy communiques published over the sample period. The top 25 words with high probabilities of appearing under each of the six topics are listed in Table 4. As hinted by Debortoli et al. (2016), labels can be assigned to identified topics in a given LDA model by inspecting its most probable terms vis-a-vis the associated most probable documents. This intuition is followed in assigning labels to the six identified topics of our model. Under topic 1, the most probable terms include "exchange", "inflation", "foreign" "price", "pressure", "stability", "domestic", "mpr", "interest", "oil”, "headline", etc (Table 4, Figure 6). Based on this combination of words, we assign a description relating to "exchange rate management and exchange rate pass-through to domestic prices" to this topic. 
Table 4: Identified topics and their probable terms

\begin{tabular}{|c|c|c|c|c|c|c|}
\hline S/No. & Topic 1 & Topic 2 & Topic 3 & Topic 4 & Topic 5 & Topic 6 \\
\hline 1 & exchang & monetari & oil & bank & economi & market \\
\hline 2 & inflat & polici & growth & growth & growth & polici \\
\hline 3 & foreign & bank & fiscal & economi & market & rate \\
\hline 4 & price & target & increas & govern & polici & financi \\
\hline 5 & pressur & exchang & reserv & improv & global & sector \\
\hline 6 & stabil & money & extern & credit & monetari & develop \\
\hline 7 & liquid & continu & us\$ & continu & develop & econom \\
\hline 8 & domest & inflat & price & recoveri & remain & lend \\
\hline 9 & $\mathrm{mpr}$ & naira & output & sector & sector & growth \\
\hline 10 & expect & reserv & inflat & increas & financi & credit \\
\hline 11 & relat & credit & high & develop & increas & need \\
\hline 12 & well & remain & food & output & domest & power \\
\hline 13 & polici & system & declin & risk & bank & basi \\
\hline 14 & challeng & market & depreci & grew & econom & interbank \\
\hline 15 & interest & deposit & due & sustain & retain & facil \\
\hline 16 & inflow & rise & project & outlook & output & continu \\
\hline 17 & oil & appreci & impact & global & emerg & real \\
\hline 18 & aggreg & macroeconom & pressur & posit & oil & sustain \\
\hline 19 & fiscal & broad & core & budget & suppli & point \\
\hline 20 & grew & increas & domest & includ & vote & reform \\
\hline 21 & effect & extern & global & observ & declin & remain \\
\hline 22 & econom & foreign & condit & moder & improv & govern \\
\hline 23 & major & interest & concern & confid & low & privat \\
\hline 24 & net & privat & moder & capit & larg & petroleum \\
\hline 25 & headlin & cbn & rate & real & consider & monetari \\
\hline $\begin{array}{l}\text { Assigned } \\
\text { topic }\end{array}$ & $\begin{array}{c}\text { Exch. rate mgt. \& } \\
\text { exchange rate } \\
\text { pass-through to } \\
\text { domestic prices }\end{array}$ & $\begin{array}{l}\text { Monetary policy } \\
\& \text { macroeconomic } \\
\text { stability }\end{array}$ & $\begin{array}{l}\text { Macroeconomic } \\
\text { implications of } \\
\text { oil price shocks }\end{array}$ & $\begin{array}{c}\text { Economic } \\
\text { performance, } \\
\text { economic recovery, } \\
\text { and government } \\
\text { policies }\end{array}$ & $\begin{array}{l}\text { Economic } \\
\text { growth and } \\
\text { global } \\
\text { developments }\end{array}$ & $\begin{array}{l}\text { Policy } \\
\text { response to } \\
\text { domestic } \\
\text { contraints }\end{array}$ \\
\hline
\end{tabular}

Source: Authors' compilation

The probable terms under topic 2 include "monetary", "policy", "bank", "target", "exchange", "inflation", "reserves", "credit", "macroeconomy", "interest", "cbn", etc (Table 4, Figure 6). Therefore, we assign a description relating to "monetary policy and macroeconomic stability" to the topic. In other words, the discussions regarding the use of monetary policy to achieve monetary, price, and exchange rate stability are encapsulated under the second topic. The terms with high probabilities of appearing under topic 3 include "oil", "growth", "fiscal", "reserves", "external", "price", “output", "inflation", "reserves", "depreciation", "food", "core", etc (Table 4, Figure 6). Based on an intuitive evaluation of these words, we ascribe the third topic as covering MPC's discussions regarding the "macroeconomic implications of oil price shocks".

Next is topic 4, which encapsulates terms such as "bank", "growth", "recovery", "economic", "credit", "government", "sector", "develop", "output", "outlook" with high probabilities (Figure 6). Therefore, this topic is ascribed a label that relates to MPC's discussions about the country's "economic performance, economic recovery, and government policies". The terms featuring under topic 5 with high probabilities 
include: "economic", "growth", "market", "policies", "global", "monetary", "develop". Others include terms such as "domestic", "economy", "financing", "output". Consequently, we assign topic 5 to issues bordering on "economic growth and global developments". The sixth topic appears to focus on "policy response to domestic constraints" as the most probable terms featuring under the topic include "market", "policies", "rate", "financing", "real", "sector", "develop", “economy", "lend", "power", "petroleum", "government", etc (Table 4, Figure 6).

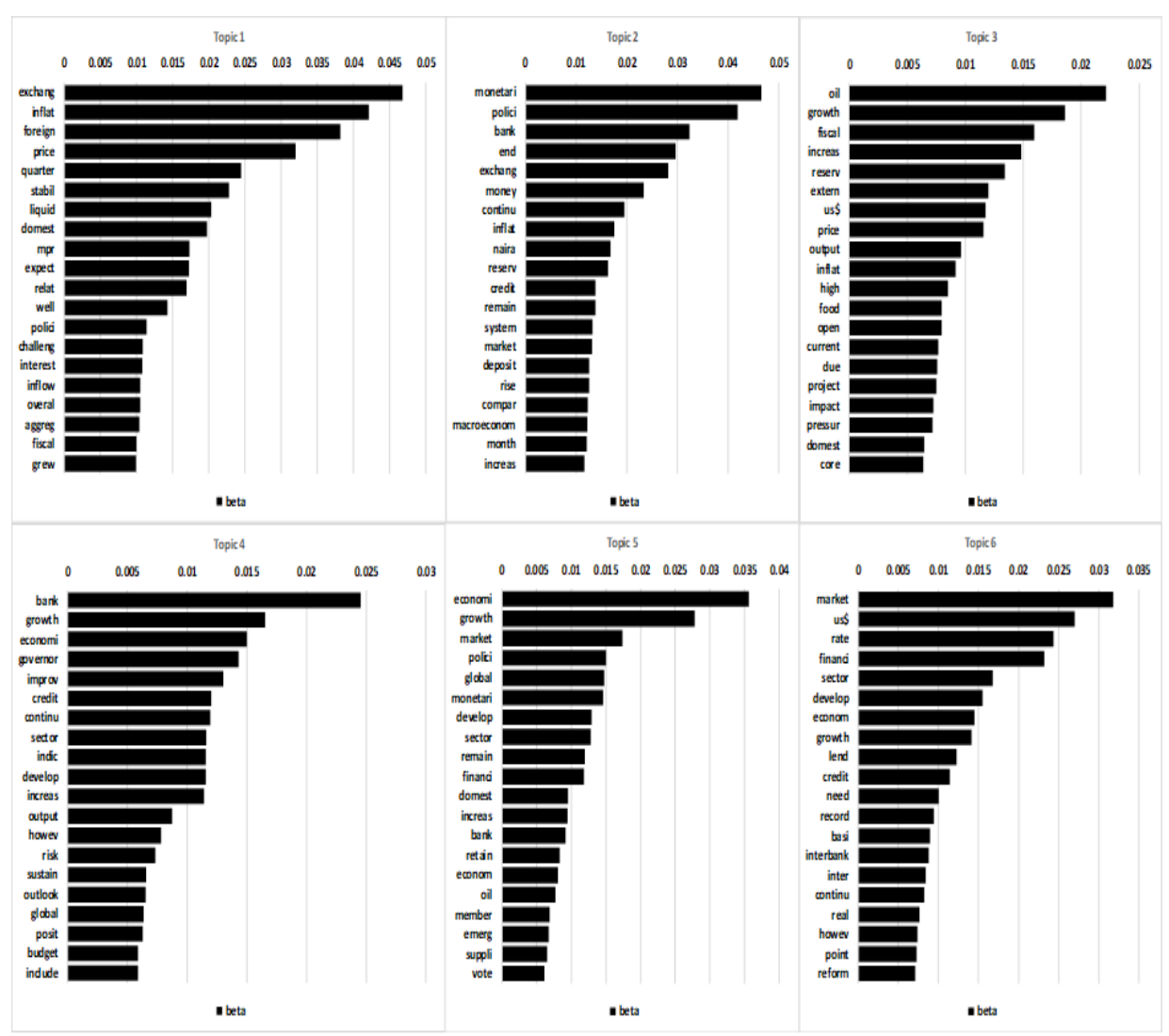

Figure 6: Most frequent terms and their probabilities of occurring under each topic

Furthermore, we analyse the evolution of the topics driving Nigeria's monetary policy communication during 2004-2019 by plotting the topic proportion for our identified topics as shown in Figure 7. It is obvious from the chart that the linguistic content of the policy communiques for the period 2004-2007 was dominated by issues bordering on monetary policy and macroeconomic stability. For instance, a portion of the first paragraph of Communique No. 53 (December 2007) reads as follows: "The Committee noted with satisfaction the sustained single -digit 
inflation throughout the year and the orderly functioning of the foreign exchange and domestic financial markets". In the second paragraph of the communique, it was also stated that "The Committee restated its commitment to ensuring continued price and monetary stability through an appropriate monetary policy stance for the rest of the year". These quotations seem to align with our ascribed label for the second topic of our LDA model.

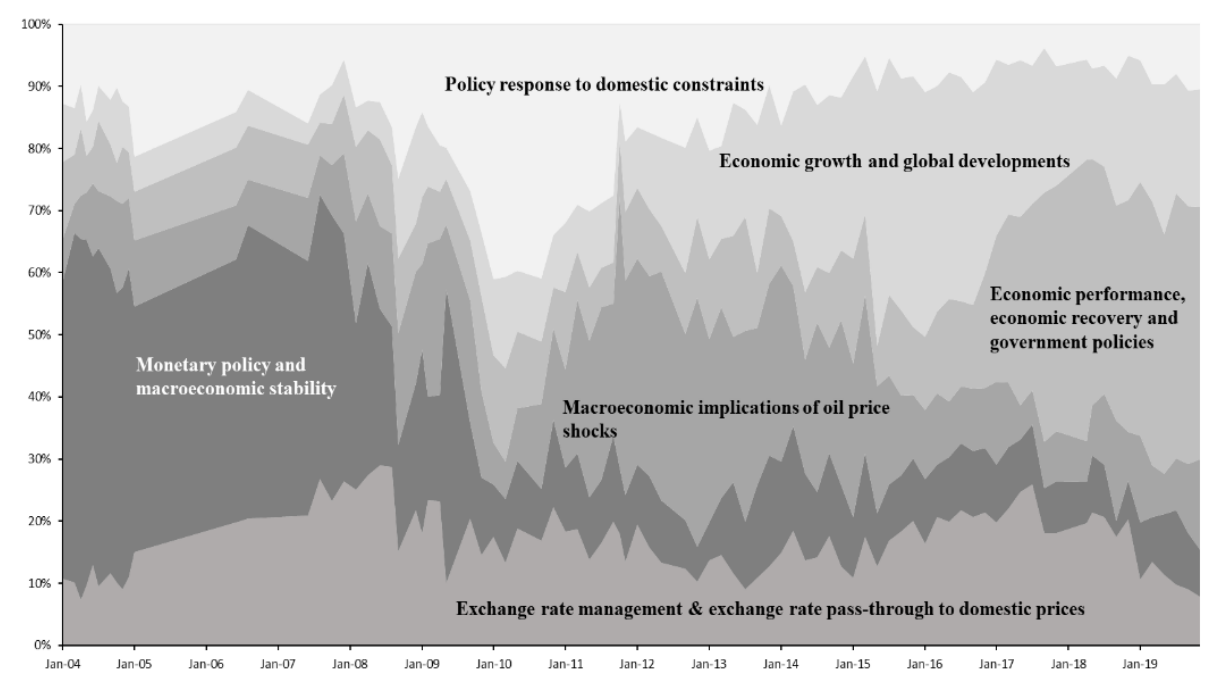

Figure 7: Topic evolution of CBN's monetary policy communication, 2004-2019

As the effects of the global financial crisis as well as the oil price slump of 2008 hit the domestic economy, the topic proportion for "policy responses to domestic constraints" increased, especially during 2009-2012 (Figure 7). This concern was expressed, for instance, in the fourth paragraph of Communique No. 67 (January 2010) as follows: “...On the domestic scene, the MPC underscored the need for strengthening ongoing reform efforts in the banking sector aimed at engendering desirable medium term economic growth path consistent with price and financial stability. It further underlined the need to fast-track the proposed reforms in some key sectors of the Nigerian economy, and in particular, the power sector, to attract the much-needed private sector/foreign investment. This, the Committee noted, was necessary because of the benefits in terms of the growth-enhancing and employment-creating potentials that these reforms and opening-up of the sectors would have on the rest of the economy". 
As shown in Figure 7, the issues relating to the impacts of global shocks on the Nigerian economy has remained an important source of concern to the MPC since 2012, reaching its peak during the economic recession of 2016. Also, being the country's major export commodity, discussions on the macroeconomic implications of oil price shocks were quite preeminent over the sample period. However, the topic proportions for this aspect of central bank communication were quite substantial during 2011-2015 as the oil price declines of 2008/09 and 2014 took its toll on the Nigerian economy. For instance, a portion of policy Communique No. 93 (January 2014) states as follows: “...This absence of fiscal buffers increased our reliance on portfolio flows thus, constituting the principal risk to exchange rate stability, especially with uncertainties around capital flows and oil price". By the end of 2014, Communique No. 98 stated that “...the global economic space continued to be dominated by strong downside risks to growth, including the softening commodity prices, rising geo-political tensions, and heightening threats to financial markets in the emerging and frontier economies in the aftermath of the termination of Quantitative Easing by the US Federal Reserve at the end of October 2014. Developments in the international oil market have intensified the risks and vulnerabilities faced by oil exporting countries in the wake of a new episode of falling oil prices". The November 2014 further notes that “.... unlike in previous episodes, the current downturn in oil prices is not transitory but appears to be permanent; being a product of technological advancement". These concerns support our description of topic 3 and explain the dominance of the topic proportion during the 2011-2015 period.

As earlier noted, the Nigerian economy got into a recession in 2016 driven largely by negative oil price shocks as well as other developments in the global economy. For instance, the second paragraph of Communique No. 107 (May 2016) reads "... The Committee noted with concern, the tapered growth and continued decline in global output since 2014. At an estimated 3.2 per cent, global output in 2016 was only 0.1 percentage point below the 3.1 per cent in the corresponding period of 2015. The sluggish global output was traced to weak fundamentals in both the advanced economies and Emerging Markets and Developing Economies (EMDEs), including increased volatility in global financial markets, sustained softness in commodity prices, sluggish global trade, resulting in persistent fragility, particularly in the EMDEs". Expectedly, the topic proportion relating to economic growth increased substantially during 2015 and the first half of 
2016 after which the GDP growth reached its trough and recorded an inflexion. It is also important to note that the topic proportion relating to exchange rate management and exchange rate pass-through to domestic prices increased during $2016-2017$, reflecting the foreign exchange market pressures of 2015 and the exchange rate reforms implemented in June 2016. Consequently, the MPR was increased in the July 2016 meeting of the monetary policy committee.

Finally, the results of our topic model show that issues relating to "economic performance, economic recovery and government policies" dominated during the MPC meetings of 2018-2019 (Figure 7). This finding is consistent with the fifth paragraph of Communique No. 117 (April 2018), which stated as follows: “...The Committee believes that effective implementation of the Economic Recovery and Growth Plan (ERGP) by the Federal Government and quick passage of the 2018 budget will continue to enhance aggregate demand and confidence in the Nigerian economy". Another portion of the communique reads thus: "The Committee noted with satisfaction the gradual return to macroeconomic stability as reflected in the third consecutive quarterly growth in real GDP in the fourth quarter of 2017'. It is also important to observe that the topic proportion for "exchange rate management and exchange rate passthrough to domestic prices" is generally substantial across the sample period, indicating the CBN's commitment to the achievement of price and exchange rate stability.

\subsection{Monetary policy sentiment analysis}

In Figure 8, we show the plot of the computed monetary policy net sentiment score (MPSS) for the period 2004 - 2019. The average MPSS for the 2004-2019 period was -10.5 per cent, implying that the MPC was inundated by policy uncertainties generated by various global and domestic economic shocks during the sample period. The analysis of the evolution of the MPSS can be conducted in line with the results of our topic model discussed in sub-section 4.5. For instance, the dip in the MPSS recorded in 2016 reflects the economic recession witnessed by the country.

The lowest MPSS, which was recorded in July 2004 reflects the MPC's perception regarding the potential risks to the attainment of its policy objectives with respect to price, exchange rate, and monetary stability. On the other hand, the MPSS peaked in January 2009 with the MPC expressing its satisfaction about the performance of the economy, 
especially with regards to economic growth. For instance, in the second paragraph of Communique No. 60, it was stated that the MPC “....noted that the preliminary estimate of the GDP growth rate for the end of 2008 was an impressive $6.8 \%$ compared with $6.2 \%$ in 2007 ". The policy communique of May 2011 also expressed net positive sentiments amidst the observed recovery in the global economy as well as stability in the domestic economy.

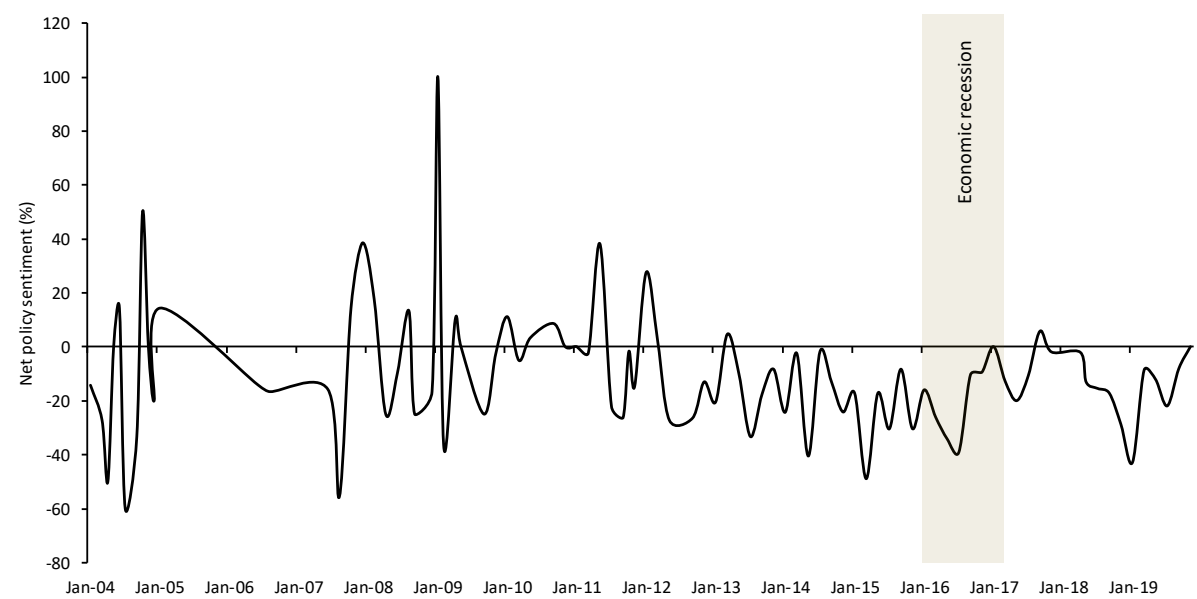

Source: Authors' computation

Figure 8: CBN's monetary policy net sentiment score, $2004-2019$

Despite the economy's exit from recession beginning in 2017, the MPC expressed substantial negative sentiments in January 2019. The negative MPSS recorded during this period was due to global economic uncertainties and the declining oil prices. This sentiment was, for instance, expressed in the first paragraph of Communique No. 122 as follows: "The Monetary Policy Committee (MPC) held its first meeting for fiscal 2019 on 21st and 22nd January 2019 amidst concerns over the slowdown in global economic activity, arising from on-going trade tensions, tightening global financing conditions and mounting external debt in Emerging Market and Developing Economies (EMDEs). On the domestic front, the resurgence of moderate inflationary pressure and possible threats to accretion to external reserves due to softening crude oil prices were noted". While this study is not aimed at providing a detailed analysis of the evolution of the MPSS over the sample period, we note that subsequent effort can pursue this area of research further. In addition, the relationship between the computed MPSS and relevant macroeconomic variables such 
as output growth, inflation, stock returns, interest rates, etc can be explored.

\subsection{Conclusion}

Effective central bank communication is an important tool for adequately shaping market expectations and enhancing monetary policy effectiveness. This paper examined the communication strategy of the CBN during the period 2004-2019 by analysing the policy communiques published by the Bank on its website. Our results showed that the CBN has increased its communication over the years, providing evidence of increased monetary policy transparency. However, the computed readability scores indicated that the policy communiques have become less understandable over time.

Furthermore, results from our estimated topic model showed that the topic relating to monetary policy and macroeconomic stability was predominant during 2004-2007. Also, following the oil price increases of 2009-2011 and the relative macroeconomic stability recorded during the period, the topic proportion for issues relating to the implementation of policies aimed at addressing domestic constraints increased in September 2009, reaching a peak in May 2011. This topic proportion also began to increase in 2018 reflecting the Bank's efforts towards encouraging the DMBs to lend to the real sector. The topic proportion relating to economic growth and global developments reached its peak in 2016, reflecting the MPC's concern about the economic recession recorded during the year. Generally, the topic evolution of monetary policy communication appeared to be largely influenced by the CBN's announced policy objectives as well as the consternation of shocks hitting the economy each period. The average monetary policy net sentiment score for the documents in our corpus was computed as -10.5 per cent. This level of negative sentiment is reflective of the global and domestic uncertainties faced by the economy as well as the MPC's perception about macroeconomic developments and outlook during the sample period.

To our knowledge, this paper represents a pioneering effort at studying central bank communication in Nigeria using automated text mining techniques. It is hoped that future efforts will push this research frontier forward by investigating the empirical relationship between text-based indicators of central bank communication and relevant macroeconomic variables, such as the exchange rate, stock market returns, GDP growth, 
amongst others. The usefulness of text-based indicators of central bank communication (such as the monetary policy sentiment score) for improving monetary policy prediction in Nigeria can also be explored.

\section{References}

Amadxarif, Z., Brookes, J., Garbarino, N., Patel, R., \& Walczak, E. (2019). The language of rules: Textual complexity in banking reforms. Bank of England Working Paper.

Amusa, L., Yahya, W, . \& Balogun, A. (2016). Data mining of Nigerian's sentiments on the administration of federal government of Nigeria. Annals. Computer Science Series, 14(2).

Apel, M., \& Grimaldi, M. (2012). The information content of central bank minutes. Riksbank Research Paper Series, (92).

Apel, M., \& Grimaldi, M. B. (2014). How informative are central bank minutes? Review of Economics, 65(1), 53-76.

Barbagallo, D., Bruni, L., Francalanci, C. \& Giacomazzi, P. (2012). An empirical study on the relationship between twitter sentiment and influence in the tourism domain, in 'Information and Communication Technologies in Tourism 2012', Springer, pp. 506- 516.

Berger, H., Ehrmann, M., \& Fratzscher, M. (2011). Monetary policy in the media. Journal of Money, Credit and Banking, 43(4), 689709 .

Bergholt, D. (2014). Monetary policy in oil exporting economies. Working paper 0023, Centre for Applied Macro-and Petroleum economics (CAMP), BI Norwegian Business School.

Bernanke, B. S., Gertler, M., Watson, M., Sims, C. A., \& Friedman, B. M. (1997). Systematic monetary policy and the effects of oil price shocks. Brookings Papers on Economic Activity, 1997(1), 91-157.

Bernanke, B. S., \& Reinhart, V. R. (2004). Conducting monetary policy at very low short-term interest rates. American Economic Review 94(2), 85-90.

Bholat, D., Hansen, S., Santos, P., \& Schonhardt-Bailey, C. (2015). Text mining for central banks. Available at SSRN 2624811. 
Binette, A. \& Tchebotarev, D. (2019). Canada's monetary policy report: If text could speak, what would it say? Bank of Canada Staff Analytical Note.

Blei, D. M., Ng, A. Y., \& Jordan, M. I. (2003). Latent Dirichlet allocation. Journal of Machine Learning research. 3(Jan), 9931022 .

Blinder, A. S. (1999). Central Banking in Theory and Practice. MIT press.

Blinder, A. S., Ehrmann, M., Fratzscher, M., De Haan, J., \& Jansen, D. J. (2008). Central bank communication and monetary policy: A Survey of Theory \& Evidence. Journal of Economic Literature. 46(4), 910-45.

Born, B., Ehrmann, M., \& Fratzscher, M. (2014). Central bank communication on financial stability. The Economic Journal 124(577), 701-734.

Bruno, G. (2016). Text mining and sentiment extraction in central bank documents, in 2016 IEEE International Conference on Big Data (Big Data). IEEE, pp. 1700-1708.

Bruno, G. (2017). Central bank communications: Information extraction and semantic analysis. IFC Bulletins chapters 44.

Calvo-González, O., Eizmendi, A., \& Reyes, G. J. (2018). Winners never quit, quitters never grow: using text mining to measure policy volatility and its link with long-term growth in latin America. World Bank Policy Research Working Paper. (8310).

Clarida, R., Gali, J., \& Gertler, M. (2000). Monetary policy rules and macroeconomic stability: Evidence and some theory. The Quarterly journal of economics. 115(1), 147- 180.

Coenen, G., Ehrmann, M., Gaballo, G., Hoffmann, P., Nakov, A., Nardelli, S., Persson, E., \& Strasser, G. (2017). Communication of monetary policy in unconventional times. ECB Working Paper. No. 2080.

Coleman, M., \& Liau, T. L. (1975). A computer readability formula designed for machine scoring. Journal of Applied Psychology. 60(2), 283. 
Correa, R., Garud, K., Londono, J. M., \& Mislang, N. (2017). Sentiment in central banks' financial stability reports. International Finance Discussion Papers 1203.

Crone, S. F., \& Koeppel, C. (2014). Predicting exchange rates with sentiment indicators: An empirical evaluation using text mining and multilayer perceptrons, in 2014 IEEE Conference on Computational Intelligence for Financial Engineering and Economics (CIFEr), IEEE. 114-121.

Daas, P. J., \& Puts, M. J. (2014). Social media sentiment and consumer confidence. ECB Statistics Paper.

Debortoli, S., Müller, O., Junglas, I., \& Vom Brocke, J. (2016). Text mining for information systems researchers: An annotated topic modelling tutorial. Communications of the Association for Information Systems. 39(1), 7.

Demiralp, S., Kara, H., \& Ozlu, P. (2012). Monetary policy communication in turkey. European Journal of Political Economy. 28(4), 540-556.

Ehrmann, M., \& Fratzscher, M. (2005). Communication and decisionmaking by central bank committees. ECB Working Paper.

Ekor, M., Adeniyi, O., \& Saka, J. (2013). Central bank communication and monetary policy effectiveness: Empirical evidence from Nigeria. University Library of Munich, Germany. 118-152.

Eusepi, S. (2010). Central bank communication and the liquidity trap. Journal of Money, Credit and Banking. 42(2-3), 373-397.

Eusepi, S., \& Preston, B. (2010). Central bank communication and expectations stabilization. American Economic Journal: Macroeconomics. 2(3), 235-71.

Farina, V., Galloppo, G., \& Previati, D. A. (2018). Central banks' communication strategies: Just words? in Contemporary Issues in Banking, Springer, pp. 91-121.

Gefen, D., Endicott, J. E., Fresneda, J. E., Miller, J. L., \& Larsen, K. R. (2017). A guide to text analysis with latent semantic analysis in $\mathrm{R}$ with annotated code: Studying online reviews and the stack exchange community. CAIS. 41, 21. 
Geraats, P. M. (2002). Central bank transparency. The Economic Journal. 112(483), F532- F565.

Hayo, B., \& Neuenkirch, M. (2011). Canadian interest rate setting: the information content of Canadian and us central bank communication. Southern Economic Journal. 78(1), 131-148.

Hoeberichts, M., Tesfaselassie, M. F., \& Eijffinger, S. (2008). Central bank communication and output stabilization. Oxford Economic Papers. 61(2), 395-411.

Hopper, G. P. (1997). What determines the exchange rate: Economic factors or market sentiment. Business Review. 5, 17-29.

Huang, K. X. (2007). Effective central bank communication under uncertainty. Journal of Economic Issues. 41(3), 661-680.

Hubert, P., \& Fabien, L. (2017). Central bank sentiment and policy expectations. Bank of England Staff Working Paper 648.

Iwantoro, T., \& Koesrindartoto, D. P. (2017). Exchange rate directional forecasting using sentiment analysis on social media in Indonesia. Australian Academy of Accounting and Finance Review. 1(2), 132-147.

Janetzko, D. (2014). Predictive modelling in turbulent times-what twitter reveals about the EUR/USD exchange rate. NETNOMICS: Economic Research and Electronic Networking. 15(2), 69-106.

Kahveci, E., \& Odabas, A. (2016). Central bank's communication strategy and content analysis of monetary policy statements: The case of Fed, ECB and CBRT. Procedia-Social and Behavioural Sciences. 235, 618-629.

Khatri, S. K., Singhal, H. \& Johri, P. (2014). Sentiment analysis to predict bombay stock exchange using artificial neural network, in Proceedings of 3rd International Conference on Reliability, Infocom Technologies and Optimization. IEEE. pp. 1-5.

Kumar, S., Maskara, S., Chandak, N., \& Goswami, S. (2015). Empirical study of relationship between twitter mood and stock market from an indian context. International Journal of Applied Information Systems. 8(7), 33-37. 
Luangaram, P., \& Sethapramote, Y. (2016). Central bank communication and monetary policy effectiveness: Evidence from Thailand. Puey Ungphakorn Institute for Economic Research.

Luangaram, P., \& Wongwachara, W. (2017). More than words: A textual analysis of monetary policy communication. PIER Discussion Papers. 54.

Miner, G., Elder IV, J., Fast, A., Hill, T., Nisbet, R., \& Delen, D. (2012). Practical text mining and statistical analysis for non-structured text data applications. Academic Press.

Mittal, A., \& Goel, A. (2012). Stock prediction using twitter sentiment analysis. Stanford University Working Paper 15.

Naghdaliyev, N. S. (2011). Central banks' communication in the postcrisis period. The Harriman Institute, Columbia University.

Nyman, P. O. R., \& Tuckett, D. (2015). Measuring financial sentiment to predict financial instability: A new approach based on text analysis. University College London.

Omotosho, B. S. (2020). Central bank communication in Ghana: insights from a text mining analysis. Noble International Journal of Economics and Financial Research. 5(1), 1-13.

Oshima, Y., \& Matsubayashi, Y. (2018). Monetary policy communication of the bank of Japan: Computational text analysis. Graduate School of Economics Working paper, Kobe University.

Ozturk, S. S., \& Ciftci, K. (2014). A Sentiment Analysis of Twitter Content as a Predictor of Exchange Rate Movements. Review of Economic Analysis. 6(2), 132-140.

Park, K. Y., Lee, Y., \& Kim, S. (2019). Deciphering monetary policy board minutes through text mining approach: The case of Korea. Bank of Korea Working Paper.

Plakandaras, V., Papadimitriou, T., Gogas, P., \& Diamantaras, K. (2015). Market sentiment and exchange rate directional forecasting. Algorithmic Finance. 4(1-2), 69-79.

Poole, W. (2005). Remarks: Panel on after Greenspan: Whither Fed policy? Remarks delivered at the Western Economics 
Association International conference, San Francisco, California.

Ranco, G., Aleksovski, D., Caldarelli, G., Grčar, M., \& Mozetič, I. (2015). The Effects of twitter sentiment on stock price returns. PloS One. 10(9), e0138441.

Sanusi, A. R. (2011). Signalling effects of monetary policy in nigeria: Evidence from the new Central Bank's communication regime: 2005-2011, in 52nd Annual Conference of the Nigerian Economics Society.

Shapiro, A. H., \& Wilson, D. (2019). Taking the Feds at its word: Direct estimation of central bank objectives using text analytics. Federal Reserve Bank of San Francisco Working Paper 201902 .

Shirota, Y., Hashimoto, T., \& Sakura, T. (2015). Topic extraction analysis for monetary policy minutes of Japan in 2014, in Industrial Conference on Data Mining. Springer, pp. 141-152.

Siklos, P. L. (2013). The global financial crisis and the language of central banking: Central bank guidance in good times and in bad. CAMA Working Paper Series Paper 58/2013.

Sturm, J.-E., \& De Haan, J. (2011). Does central bank communication really lead to better forecasts of policy decisions? New evidence based on a taylor rule model for the ECB. Review of World Economics. 147(1), 41-58.

Sumbureru, P. T. (2013). Analysis of tweets for prediction of indian stock markets. International Journal of Science and Research (IJSR). 4(8), $1168-1172$.

Umar, S., \& Sanusi, A. R. (2013). Impact of central bank communications on stock prices in nigeria (2007 - 2011). Economic Update: Nigerian Journal of Contemporary Public Policy Issues. 7(2), 1-28.

Woodford, M. (2002). Monetary policy in the information economy. Technology and the New Economy. MIT Press. 187-273. 
Woodford, Michael. (2005). Central bank communication and policy effectiveness, in The Greenspan Era: Lessons for the Future. Kansas City: Federal Reserve Bank of Kansas City, 399-474.

Yahaya, E., \& Sanusi, A. R. (2012). An empirical analysis of the effects of central bank communications on money market volatility in Nigeria: 2007-2011. Economic Update: Nigerian Journal of Contemporary Public Policy Issues. 6(1), 1 -34. 